\title{
As Práticas Pedagógicas nos Livros Didáticos de Ciências e de Biologia Recomendados pelo PNLD 2017 e pelo PNLEM 2018
}

\section{Pedagogical Practices in Science and Biology Teaching Books Recommended by PNLD 2017 and PNLEM 2018}

\author{
Andressa Corcete Hartmann*a; Erica do Espírito Santo Hermel ${ }^{a}$ \\ ${ }^{a}$ Universidade Federal da Fronteira Sul, Curso de Ciências Biológicas. RS, Brasil. \\ *E-mail: andressahartmann06@gmail.com.
}

\begin{abstract}
Resumo
O presente trabalho teve como objetivo analisar e investigar as Práticas Pedagógicas presentes nos Livros Didáticos de Ciências e Biologia recomendados pelo PNLD 2017 e pelo PNLEM 2018. Para tanto, foram analisadas duas coleções de livros didáticos de Ciências (8 livros) e duas de Biologia (6 livros). A análise dos Livros Didáticos ocorreu em três etapas: primeiramente, foi realizada a leitura das Práticas Pedagógicas, logo após estas foram classificadas em categorias: Esquema de representação; Atividade de texto; Questões de Enem e de vestibular; Leitura complementar; Sugestões de práticas; Tema para discussão; Saiba mais; Questões discursivas; Ciências, tecnologia e sociedade; Exercícios comentados; Curiosidades; Atividades em grupo; Pense e responda; Questionários; Atividades reproducionistas; Tabelas, gráficos e mapas conceituais; Sugestão de pesquisa, sites, redação ou resumo; Atividades reflexivas, tirinhas e palavras cruzadas. Para finalizar foi realizada a contextualização utilizando referencial teórico. Ao total foram encontradas 5903 Práticas Pedagógicas, sendo 3451 nas coleções de Ciências e 2452 nas coleções de Biologia. A categoria que mais se destacou nos livros analisados, nesta pesquisa, foi a atividade reproducionista com 1359 práticas e a que menos se destacou foi a de projeto interdisciplinar com 12. Apesar do grande número de Práticas Pedagógicas encontradas nos livros didáticos, a maioria se limitava a poucas categorias, refletindo a pouca diversidade de estratégias de consolidação do conhecimento utilizadas nos livros.
\end{abstract}

Palavras-chave: Recursos Didáticos. Currículo. Ensino de Ciências. Ensino de Biologia.

\begin{abstract}
The study herein aimed to analyze and investigate the Pedagogical Practices present in the Textbooks of Science and Biology, recommended by PNLD 2017 and PNLEM 2018. To this end, two collections of science textbooks (8 books) and two biology textbooks (6 books) were analyzed. The didactic books analysis took place in three stages: first reading the Pedagogical Practices, soon after they were classified into categories. : Scheme of representation; Text activity; Enem and college entrance exams; Complementary reading; Suggestions of practices; Theme for discussion; Know more; Discursive questions; Science, technology and society; Commented exercises; Curiosities; Group activities; Think and answer; Questionnaires; Reproduction activities; Tables, graphs and concept maps; Search suggestion, websites, writing or summary; Reflective activities, comics and crossword puzzles. In order to finalize the contextualization using the theoretical framework was performed. A total of 5903 Pedagogical Practices were found, 3451 in the Science collections and 2452 in the Biology collections. The category that stood out most in the books analyzed in this research was the reproductive activity with 1359 practices and the one that stood out the most was the interdisciplinary project with 12. Despite the large number of Pedagogical Practices found in textbooks, most of them were limited to a few categories, reflecting the limited diversity of knowledge consolidation strategies used in textbooks.
\end{abstract}

Keywords: Didactic Resource. Curriculum. Biology Teaching. Teaching and Learning.

\section{Introdução}

Os livros didáticos (LD) abordam saberes sistematizados e, segundo Apple (1995), os textos desses livros representam, frequentemente, uma cultura legítima a ser transmitida nas disciplinas escolares. Com isso, os LD conseguem facilitar a troca de conhecimento entre alunos e professores, em sala de aula, e uma das principais formas de tornar essa troca mais efetiva é com as Práticas Pedagógicas (PP) presentes nesses livros.

No Brasil, o uso de LD é reportado desde o período imperial, porém, na década de 1930, foi criado o Instituto Nacional do Livro (INL), com a função de cuidar e ampliar a produção de LD. Posteriormente, em 1938, foi editado o
Decreto-Lei 1006, o qual estabelece as condições de produção, de importação e de utilização de LD, sendo o marco norteador nas suas edições. Já, em 1985, a partir do Decreto n 9154, foi criado o Programa Nacional do Livro Didático (PNLD), que estabeleceu, entre outros critérios, a avaliação periódica dos LD (ZACHEU; CASTRO, 2014).

Porém, apenas a partir da década de 1990, houve o início de discussão sobre os LD para o Ensino Fundamental. Em 1996, foi criada a Lei n 9394, que estabeleceu as Diretrizes e Bases da Educação Nacional Escolar Brasileira (LDB), na qual foi definida a estrutura da formação básica comum, sendo que os Parâmetros Curriculares Nacionais (PCN), criados em 1997, direcionaram o ensino e aprendizado dos estudantes. 
Dessa forma, nos últimos anos são crescentes os debates e as ações voltadas aos LD, tendo em vista o incentivo, a orientação, a coordenação e a execução de propostas relacionadas com a melhora da qualidade dos LD (VASCONCELOS; SOUTO, 2003). Isso porque o LD é o principal instrumento na formação escolar sendo, por vezes, o único objeto pedagógico disponível (SILVA, 2012). No ensino de Ciências, os LD apresentam, muitas vezes, conteúdos fragmentados e padronizados, de forma que os alunos não conseguem associar os conteúdos com a sua realidade, além de dificultar a modificação e inovação nesses livros (FERNANDE; GÜLLICH; KIEREPKA, 2012).

Com isso, os LD devem ser objeto de constantes pesquisas relacionadas com a PP, pois são fundamentais para a consolidação de conhecimentos pelo professor e aprendizado duradouro dos alunos e, assim, melhorar a qualidade de ensino, principalmente, o público, pois os LD são distribuídos às escolas públicas pelo Governo Federal.

O PNLD (Decreto $\mathrm{n}^{\circ}$ 91542/85) foi criado com o objetivo de distribuir LD para as escolas, para que assim todos os alunos matriculados no Ensino Fundamental pudessem ter acesso a estes, sendo a escolha dos LD feita pelos professores. Em 1996, estes livros passaram por uma avaliação para que os LD do PNLD 1997 pudessem entrar em circulação (BATISTA, 2001).

A avaliação dos LD para o Ensino Médio teve início apenas em 2004, com o Programa Nacional do Livro Didático do Ensino Médio (PNLEM). No início do PNLEM, esses foram disponibilizados para as disciplinas de português e matemática e, com o passar do tempo, os LD das demais disciplinas foram disponibilizados aos estudantes (BRASIL, 2019). E esses também começaram a passar por avaliações.

Essas avaliações são de suma importância para a qualidade do ensino e da aprendizagem, pois os LD exercem uma forte influência sobre alunos e professores de diferentes áreas do conhecimento. E, atualmente, ainda se têm estas avaliações, de modo que os livros que não se encaixam nos padrões de qualidade são desconsiderados do Guia do Livro Didático.

Nessa perspectiva, Xavier et al. (2006) ressaltam que o LD, no Brasil, é considerado um guia para a construção do currículo de muitas escolas, sejam essas de Ensino Fundamental ou Médio, além é claro de servirem como aparato no processo de ensino e aprendizagem dos alunos. Com isso, o LD é um instrumento muito importante no ensino, pois, muitas vezes, este é o único meio de estudo, possuindo um papel fundamental no ensino de crianças, de jovens e de adultos. Por isso, esse material necessita ser analisado com cautela pelo professor para que possa ser escolhido o mais adequado.

Além disso, o LD é um meio muito importante para a divulgação científica, associado aos conceitos, informações e materiais didáticos, sendo este um dos divulgadores científicos para os alunos (PECHULA et al., 2012). No entanto, para Megid Neto e Fracalanza (2003), muitas falhas são encontradas nesses, sendo uma das maiores críticas a sua padronização e as possíveis distorções dos conteúdos. Porém, mesmo que não se tenha um consenso sobre a capacidade do LD repassar um conteúdo de forma correta, esse é um dos métodos mais utilizados nas escolas (CHOPPIN, 2004).

Considerando os professores, as rápidas mudanças provocadas pela globalização induzem a adaptação às metodologias de ensino e um dos meios para essa adaptação é o avanço nos LD e nas PP, para que estes possam se manter atualizados e evitar prováveis equívocos. Isso, porque, segundo Kupske et al. (2012), o LD acaba se tornando um limitador no trabalho do professor, pois esse é uma ferramenta de auxílio, mas que não poderá substituí-lo na sala de aula.

Em relação aos alunos, estes devem desenvolver um senso de autonomia e de crítica. Porém, algumas pesquisas têm revelado que, por vezes, as PP são abordadas em LD, de forma desconexa e sem consistência. Por exemplo, Gulach e Crochik (2016) apresentaram uma avaliação de PP de alguns LD utilizados no $5^{\circ}$ ano do Ensino Fundamental de diversas áreas, sendo possível perceber que, muitas vezes, os livros abordam formas imperativas sobre a apresentação de trabalhos para a classe e a sua avaliação, o que pode gerar uma diluição da autoridade do professor e uma negação da própria realidade no aluno.

Desse modo, a ação docente deve ser significativa e estimular o aprendizado dos alunos e os LD e as PP devem apresentar concepções e metodologias que se adequam à realidade do professor e do aluno.

Assim, o presente trabalho visa analisar as PP presentes nos LD de Ciências do $6^{\circ}$ ao $9^{\circ}$ ano do Ensino Fundamental, recomendados pelo PNLD 2017 e de Biologia do $1^{\circ}$ ao $3^{\circ}$ do Ensino Médio, sendo esses recomendados pelo PNLEM 2018.

\section{Material e Métodos}

Foi realizada uma pesquisa qualitativa, do tipo documental. Segundo Lüdke e André (2001, p. 38): “a análise documental pode se constituir em uma técnica valiosa de abordagem de dados qualitativos seja complementando as informações obtidas por outras técnicas, seja desvelando aspectos novos de um tema ou problema".

Com isso, foram analisadas as PP em 14 livros didáticos de Ciências e Biologia recomendados pelo PNLD 2017 e pelo PNLEM 2018, respectivamente, sendo uma coleção de Ciências e uma de Biologia para cada escola. Esses materiais foram identificados como $\mathrm{C} 1$...C8 para Ciências e B1...B6 para Biologia (Quadro 1). 
Quadro 1 - Livros didáticos de Ciências e Biologia analisados neste trabalho

\begin{tabular}{|c|c|c|}
\hline \multicolumn{2}{|c|}{ Livros } & Referências \\
\hline \multirow{8}{*}{$\begin{array}{l}\text { PNLD } \\
2017\end{array}$} & $\mathrm{C} 1$ & $\begin{array}{l}\text { Gewandsznajder, F. Projeto Teláris Ciências 6º } \\
\text { ano: planeta terra. São Paulo: Ática, } 2015 .\end{array}$ \\
\hline & $\mathrm{C} 2$ & $\begin{array}{l}\text { Gewandsznajder, F. Projeto Teláris Ciências } 7^{\circ} \\
\text { ano: vida na terra. São Paulo: Ática, } 2012 .\end{array}$ \\
\hline & C3 & $\begin{array}{l}\text { Gewandsznajder, F. Projeto Teláris Ciências } 8^{\circ} \\
\text { ano: nosso corpo. São Paulo: Ática, } 2015 .\end{array}$ \\
\hline & $\mathrm{C} 4$ & $\begin{array}{l}\text { Gewandsznajder, F. Projeto Teláris Ciências } 9^{\circ} \\
\text { ano: matéria e energia. São Paulo: Ática, } 2015 .\end{array}$ \\
\hline & $\mathrm{C} 5$ & $\begin{array}{l}\text { Gowdak, D.O.; Martins, E.L. Ciências novo } \\
\text { pensar, } 6^{\circ} \text { ano. São Paulo: FD, } 2015 .\end{array}$ \\
\hline & C6 & $\begin{array}{l}\text { Gowdak, D.O.; Martins, E.L. Ciências novo } \\
\text { pensar, } 7^{\circ} \text { ano. São Paulo: FD, } 2015 .\end{array}$ \\
\hline & C7 & $\begin{array}{l}\text { Gowdak, D.O.; Martins, E.L. Ciências Novo } \\
\text { Pensar, } 8^{\circ} \text { ano. São Paulo: FD, } 2015 .\end{array}$ \\
\hline & $\mathrm{C} 8$ & $\begin{array}{l}\text { Gowdak, D.O.; Martins, E.L. Ciências Novo } \\
\text { Pensar, } 9^{\circ} \text { ano. São Paulo: FD, } 2015 .\end{array}$ \\
\hline \multirow{6}{*}{$\begin{array}{l}\text { PNLEM } \\
2018\end{array}$} & B1 & $\begin{array}{l}\text { Amabis, J.M.; Martho, G.R. Biologia Moderna. } \\
\text { São Paulo: Moderna, } 2016 .\end{array}$ \\
\hline & B2 & $\begin{array}{l}\text { Amabis, J.M.; Martho, G.R. Biologia Moderna. } \\
\text { São Paulo: Moderna, } 2016 .\end{array}$ \\
\hline & B3 & $\begin{array}{l}\text { Amabis, J.M.; Martho, G.R. Biologia Moderna. } \\
\text { São Paulo: Moderna, } 2016 .\end{array}$ \\
\hline & B4 & $\begin{array}{l}\text { Silva Júnior, C.; Sasson, S.; Caldini Júnior, N. } \\
\text { Biologia. São Paulo: Saraiva, 2016. v.1 }\end{array}$ \\
\hline & B5 & $\begin{array}{l}\text { Silva Júnior, C.; Sasson, S.; Caldini Júnior, N. } \\
\text { Biologia. Vol. 2. São Paulo: Saraiva, 2016. v.2 }\end{array}$ \\
\hline & B6 & $\begin{array}{l}\text { Silva Júnior, C.; Sasson, S.; Caldini Júnior, N. } \\
\text { Biologia. Vol. 3. São Paulo: Saraiva, 2016. v.3 }\end{array}$ \\
\hline
\end{tabular}

Para análise foram utilizadas as categorias adaptadas de Ribeiro et al. (2017) e Kupske et al. (2012): esquema de representação; atividade de texto; questões de ENEM e de vestibular; leitura complementar; sugestões de aula práticas; tema para discussão; saiba mais; questões discursivas; ciências, tecnologia e sociedade; exercícios comentados; curiosidades; atividades em grupo; pense e responda; questionários; atividades reproducionistas; tabelas, gráficos; sugestão de pesquisa, sites, sugestão de redação ou resumo; e tirinhas.

A análise dos LD foi realizada em três etapas: primeiramente, foi realizada a leitura das PP, que, posteriormente, foram analisadas, seguindo a classificação de acordo com as categorias supracitadas e, por fim, foi realizada a contextualização utilizando o referencial teórico.

\section{Resultados e Discussão}

As PP têm um papel muito importante no ensino e na aprendizagem dos alunos, pois segundo Fagundes (2007, p. 333) estas: “[...] são fonte geradora de perguntas e de formulação de hipóteses explicativas, bem como de respostas para os problemas em questão".

Sendo assim, na presente pesquisa foram analisadas 5.903 PP presentes em 14 livros didáticos que fizeram parte do corpo de análise. Destes, oito são referentes ao Ensino Fundamental e seis são referentes ao Ensino Médio. Nas coleções de Ciências foram encontradas 3.451 PP e nas coleções de Biologia 2.452 PP.

O Quadro 2 apresenta as PP que foram analisadas e a proporção encontrada em cada LD analisado, além da soma de todas as práticas analisadas.

Quadro 2 - Classificação das Práticas Pedagógicas analisadas dos livros didáticos de Ciências e Biologia

\begin{tabular}{|c|c|c|c|c|c|c|c|c|c|c|c|c|c|c|c|}
\hline \multirow{2}{*}{$\begin{array}{l}\text { PRÁTICAS } \\
\text { PEDAGÓGICAS }\end{array}$} & \multicolumn{14}{|c|}{ LIVROS DIDÁTICOS } & \multirow{2}{*}{ TOTAL } \\
\hline & C1 & $\mathrm{C} 2$ & C3 & $\mathrm{C4}$ & C5 & C6 & C7 & $\mathrm{C8}$ & B1 & B2 & B3 & B4 & B5 & B6 & \\
\hline Esquema de Representação & 4 & 7 & 7 & 10 & 2 & 2 & 5 & 17 & 1 & 1 & 0 & 3 & 1 & 2 & 66 \\
\hline Atividade de Texto & 27 & 23 & 8 & 12 & 23 & 28 & 10 & 13 & 2 & 3 & 4 & 46 & 89 & 91 & 379 \\
\hline $\begin{array}{l}\text { Questões de ENEM e de } \\
\text { Vestibular }\end{array}$ & 0 & 0 & 0 & 0 & 0 & 0 & 0 & 0 & 81 & 108 & 58 & 113 & 120 & 119 & 599 \\
\hline Leitura Complementar & 21 & 15 & 17 & 11 & 15 & 14 & 20 & 12 & 30 & 41 & 48 & 23 & 14 & 36 & 317 \\
\hline Sugestão de Aulas Práticas & 12 & 8 & 7 & 13 & 20 & 15 & 7 & 21 & 12 & 7 & 4 & 4 & 4 & 5 & 139 \\
\hline Tema para Discussão & 0 & 1 & 8 & 2 & 40 & 52 & 35 & 40 & 0 & 0 & 0 & 0 & 0 & 0 & 178 \\
\hline Siba Mais & 7 & 12 & 11 & 8 & 17 & 16 & 18 & 16 & 0 & 0 & 2 & 7 & 0 & 0 & 114 \\
\hline Questões Discursivas & 65 & 83 & 75 & 73 & 56 & 47 & 52 & 67 & 25 & 25 & 33 & 14 & 26 & 19 & 660 \\
\hline $\begin{array}{l}\text { Ciências, Tecnologia e } \\
\text { Sociedade }\end{array}$ & 2 & 5 & 10 & 10 & 2 & 5 & 10 & 10 & 3 & 0 & 0 & 0 & 0 & 0 & 57 \\
\hline Exercícios comentados & 0 & 0 & 0 & 0 & 0 & 0 & 0 & 0 & 0 & 0 & 5 & 0 & 0 & 15 & 20 \\
\hline Curiosidade & 5 & 8 & 6 & 15 & 3 & 5 & 10 & 11 & 0 & 0 & 0 & 0 & 0 & 0 & 63 \\
\hline Atividade em Grupo & 7 & 11 & 11 & 7 & 6 & 8 & 13 & 2 & 4 & 1 & 5 & 0 & 2 & 1 & 78 \\
\hline Pense e Responda & 93 & 113 & 119 & 125 & 32 & 42 & 45 & 58 & 38 & 28 & 37 & 28 & 21 & 11 & 790 \\
\hline Questionário & 45 & 42 & 31 & 25 & 51 & 28 & 41 & 32 & 17 & 4 & 1 & 5 & 3 & 1 & 326 \\
\hline Atividades Reproducionista & 105 & 96 & 113 & 130 & 28 & 40 & 37 & 45 & 97 & 183 & 191 & 67 & 115 & 112 & 1359 \\
\hline Tabelas e Gráficos & 5 & 4 & 11 & 18 & 3 & 1 & 10 & 8 & 3 & 3 & 3 & 5 & 4 & 0 & 78 \\
\hline $\begin{array}{l}\text { Sugestroes de Pesquisa, Sites, } \\
\text { Redações, Resumos e Livros }\end{array}$ & 66 & 56 & 72 & 58 & 37 & 21 & 40 & 42 & 2 & 2 & 3 & 52 & 66 & 81 & 410 \\
\hline Tirinhas & 14 & 2 & 0 & 2 & 12 & 17 & 10 & 13 & 0 & 0 & 0 & 0 & 0 & 0 & 70 \\
\hline TOTAL & 478 & 486 & 506 & 519 & 354 & 493 & 352 & 406 & 323 & 406 & 386 & 367 & 465 & 493 & 5891 \\
\hline
\end{tabular}

Fonte: dados da pesquisa (2019) 
Em relação às dezoito categorias analisadas, a que mais se destacou na coleção do Ensino Fundamental foi a "Pense e responda", que foi encontrada em 627 PP. Um exemplo que se classificou nesta categoria foi encontrado em C2: "Um estudante afirmou que a abertura da esponja, o ósculo, era uma boca e que a cavidade central do corpo da esponja, o átrio, era seu tubo digestório. Essa afirmação não está correta. Explique por quê.” (p. 118).

Já no Ensino Médio, 163 PP foram classificadas nesta categoria, como em B5: "Uma célula da epiderme apresenta os mesmos genes que uma célula-tronco. No entanto, a célula da epiderme não consegue originar outros tipos celulares. Explique o porquê dessa diferença." (p. 162).

A categoria "Pense e Responda" visa avaliar o que o aluno compreendeu sobre o conteúdo abordado, em sala de aula, questões que devem ser respondidas pelos próprios alunos (SOUZA; VIEIRA; MELO, 2016). Porém, nos casos analisados, as perguntas propiciam respostas objetivas, não estimulando diferentes pontos de vistas dos alunos, limitando sua argumentação. As obras de Gewandsznajder (2015) são as que mais utilizam essa PP e as obras de Júnior, Sasson e Júnior (2016) são as que menos utilizam.

Nas seis coleções de Biologia analisadas se verificou um predomínio da categoria "Atividades Reproducionistas", as quais conduzem os alunos a reproduzir apenas aquilo que foi estudado, como em B3 (p. 224): "População biológica é o conjunto: a) de espécies que habitam determinada região. b) de indivíduos de mesma espécie que vivem em determinada região, cruzando-se. c) de comunidade que vivem em um biótopo. d) formado pela comunidade biológica e pelo biótopo em interação". Ou, ainda, como apresentado no B5 “[...] diferencie cones e bastonete quanto à propriedade e sensibilidade à luz." (p. 192), que solicita apenas uma reprodução do texto como resposta. Nesta categoria foram classificadas 765 PP nos seis livros analisados.

Já, nos livros de Ciências analisados, essa categoria foi mais encontrada em $\mathrm{C} 4 \mathrm{e}$, nos oito livros analisados, foram encontradas 594 práticas, como, por exemplo, em C3: "Quais são as funções que o sangue desempenha no nosso organismo." (p.106). Cabe ressaltar, ainda, que esta foi a categoria mais encontrada nos quatorze livros analisados, sendo 1.359 PP.

Segundo Kupske et al. (2012), a atividade reproducionista caracteriza-se por levar o aluno muito mais a atividade motora de procurar nas folhas anteriores do capítulo as respostas, muitas vezes em negrito, do que a refletir sobre a proposta feita. Assim, o resultado dessas atividades é o aprendizado por meio de memorização (KRASILCHICK, 1987). Nos livros analisados, essas atividades são bastante recorrentes, sendo encontradas ao final de cada capítulo. Dessa forma, o aprendizado por memorização é uma das mais utilizadas nos LD. As obras de Gewandsznajder (2015) são as que mais utilizam atividades reproducionistas, e as que menos utilizam são as obras de Gowdak e Martins (2015).

A categoria "Ciências, Tecnologia e Sociedade" visa desenvolver o conhecimento científico e tecnológico dos alunos, de modo que estes percebam que muitos processos na natureza ocorrem simultaneamente, sendo que um processo está ligado a outro (SIEMSEN; OLIVEIRA; LORENZETTI, 2016). Essa categoria nos livros analisados foi abordada de forma didática, por meio de imagens e artigos, que visam complementar o conteúdo estudado. As obras de Gewandsznajder (2015) e Gowdak e Martins (2015) são as que mais utilizam essa PP e as que menos utilizam são as obras de Júnior, Sasson e Júnior (2016).

No entanto, esta categoria foi uma das que menos se destacou, pois foram encontradas apenas $57 \mathrm{PP}$, sendo que em B2, B3, B4, B5 e B6 não foram encontradas. Essa categoria pode ser exemplificada em C3 (Figura. 1) e em B1: "A importância da fermentação para a sociedade, [...]” (p. 153).

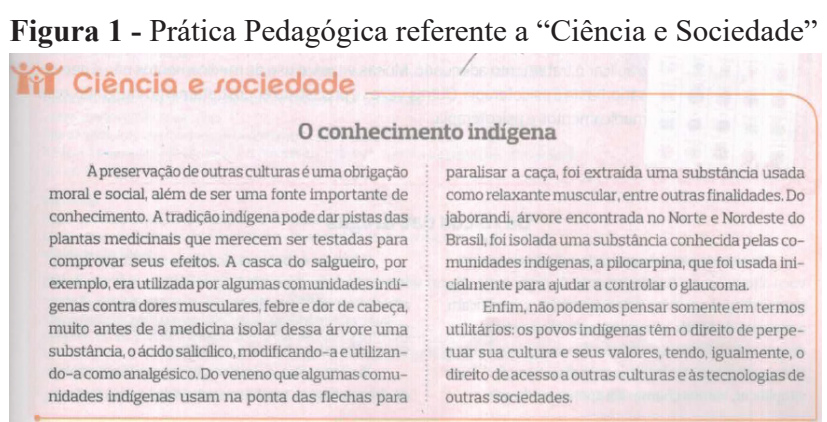

Fonte: C3.

A categoria "Sugestões de Pesquisa, Livros, Sites, Redação e Resumos" é um tipo de prática importante, pois incentiva o aluno a procurar novos conhecimentos de uma forma diferente, já que são apresentados locais nos quais devem realizar a busca (KUSPE et al., 2012). A maioria dos livros apresenta essa PP, favorecendo os conhecimentos dos alunos. As obras de Gewandsznajder (2015) são as que mais utilizam essas PP e as obras de Amabis e Martho (2016) são as que menos utilizam fontes complementares de informações.

Nesta categoria se encontra um número muito significativo de PP, principalmente, nas coleções de Ciências, com predomínio em $\mathrm{C} 1$ e $\mathrm{C} 3$, nos quais foram encontradas 66 e 72 práticas, respectivamente. Entre estas PP foram encontradas quatro redações e dois resumos. Nos demais livros foram encontradas pesquisas e sites, como em $\mathrm{C} 1$ : Observatório Sismológico, mantido pelo Instituto de Geociências da UnB, o site reúne publicações e notícias relacionadas aos fenômenos sísmicos no Brasil; e em C3: "Pesquise o que é a raquianestesia ou anestesia raquidiana por que essa tem esse nome" (p. 179). Cabe ressaltar que C2 trouxe um filme como recurso didático para ser utilizado no conteúdo de peixes, pois era recomendado no final do capítulo que fosse assistido ao filme "Procurando Nemo". Junto com a sugestão do filme são encontrados, também, três trechos (p. 173) que relatam algo sobre o filme. Além disso, foram encontradas sugestões de livros para leitura, por exemplo: "Como funciona o incrível corpo humano" em C7 (p. 72) e "Energia nossa de cada dia" em C8 (p. 34). 
Já, no Ensino Médio houve um predomínio desta categoria no livro B6, no qual foram encontradas $81 \mathrm{PP}$, como a descrita na página 268: Entendendo a evolução. Segundo Sorge et al. (2013, p.26):

As sugestões de pesquisas, sites e leituras foram consideradas como formas de buscar novos conhecimentos para o ensino, levando o aluno a ter um interesse maior no conteúdo, realizando as atividades sugeridas pelo livro ou mesmo pelo professor, causando assim, uma aproximação entre professor e aluno, um trabalhando com o outro para buscarem resultados que satisfaçam ambos.

Considerando a categoria "Exercícios Comentados", nem todos os livros apresentam essa categoria, pois, possivelmente, os autores não atribuíram a essa PP um valor pedagógico. As coleções de Gowdak e Martins (2016) e de Júnior, Sasson e Júnior (2016) apresentam exercícios resolvidos e comentados nos capítulos de genética. As obras de Júnior, Sasson e Júnior (2016) são as que mais utilizam essa PP e as obras de Gowdak e Martins (2016) são as que menos utilizam exercícios resolvidos.

Essa categoria foi encontrada em apenas dois livros (B3 e B6). Nos demais livros de Ciências e Biologia não houve PP que se classificasse nesta categoria. Entre os quatorze livros analisados foram encontras apenas vinte PP encontradas e classificadas nesta categoria. B3 é um exemplo dessa categoria (Figura 2).

Figura 2 - Exemplo de exercício comentado

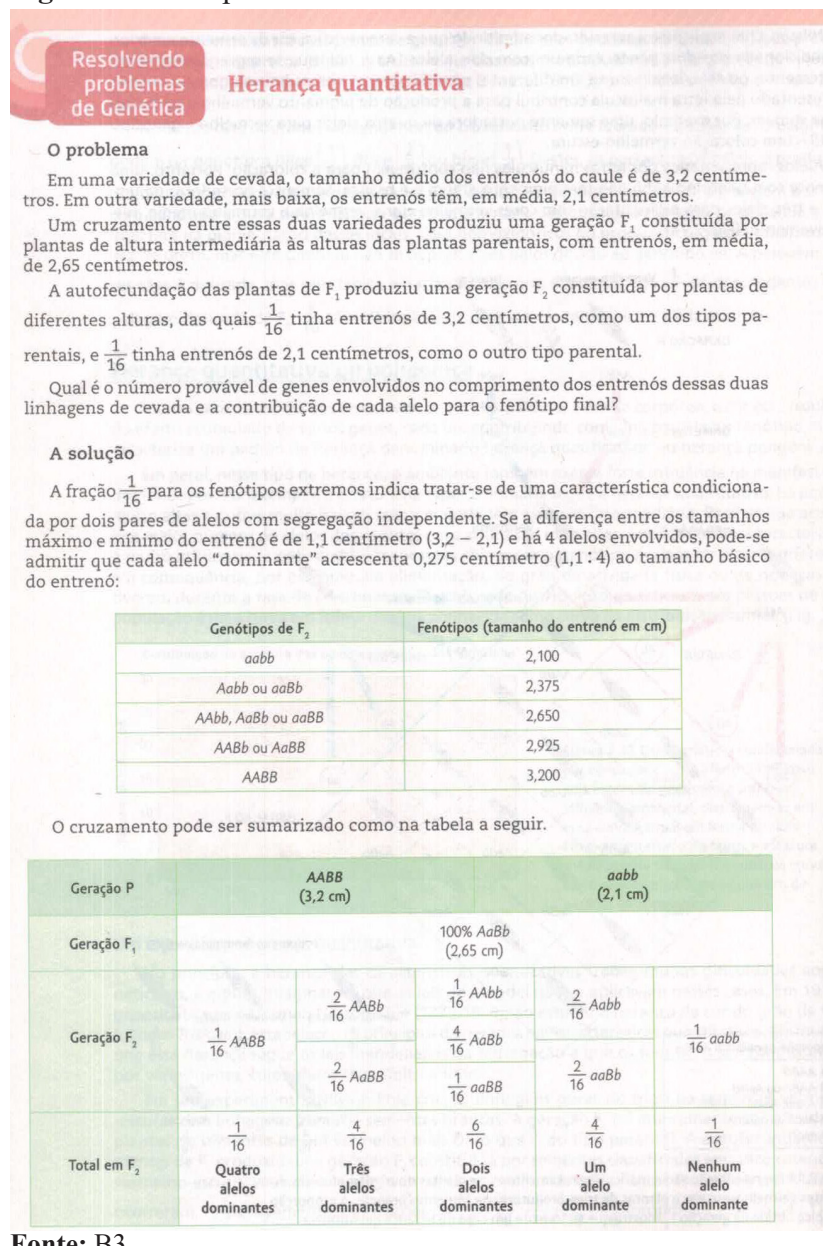

Fonte: B3.
Em relação à categoria "Questões Discursivas", foram encontradas 660 PP, sendo 518 nos livros de Ciências e 295 nos livros de Biologia. Essa categoria se sobressaiu em C2, considerando os oito livros de Ciências analisados, como por exemplo: "Por que as bactérias são importantes para o ambiente? - Por que é importante lavar as mãos antes das refeições, ao chegar da rua e depois de ir ao banheiro?" (p. 68). Essa categoria foi encontrada em seis livros de Biologia, predominando em B5, como por exemplo: "Caracterize os artrópodes" (p. 83).

A categoria "Questões Discursivas" ocorre quando o aluno pode responder as atividades com suas palavras. A categoria "questões de ENEM e de Vestibular" aborda questões dos principais testes utilizados na entrada de estudantes nas Universidades. A primeira categoria predominou no livro do autor Gewandsznajder (2015) e na categoria "questões de ENEM e de Vestibular" houve predomínio no livro do autor Júnior, Sasson e Júnior (2016). Já, os livros de Amabis e Martho (2016) e Júnior, Sasson e Júnior (2016) foram os que apresentaram menos práticas relacionadas a essas duas categorias.

A categoria "questões de ENEM e de Vestibular" foram encontradas em 599 PP, sendo possível observar que deste total, a grande maioria era de questões de Vestibulares, tendo alguns capítulos que não traziam nenhuma atividade de ENEM. Esta categoria foi encontrada apenas nos livros de Biologia, em que B1 e B3 foram os que menos apresentaram atividades, enquanto B5 foi o que mais se destacou entre os seis livros analisados.

Tem-se como exemplo a atividade do livro B3: "(ENEMMEC) A falta de água doce no planeta será, possivelmente, um dos mais graves problemas deste século. Prevê-se que, nos próximos vinte anos, a quantidade de água doce disponível para cada habitante será drasticamente reduzida. Por meio de seus diferentes uso e consumo, as atividades humanas interferem no ciclo da água, alterando a) a quantidade total, mas não a qualidade da água disponível no Planeta. b) a qualidade da água e sua quantidade disponível para o consumo das populações. c) a qualidade da água disponível, apenas no subsolo terrestre. d) apenas a disponibilidade de água superficial existente nos rios e lagos. e) o regime de chuvas, mas não a quantidade de água disponível no Planeta” (p. 210).

A seguir se traz uma prática classificada nesta categoria, encontrada em B5: “(UFRGS) Os peixes teleósteos podem ser encontrados em ambientes de água doce e em ambientes marinhos. O comportamento osmótico desses animais é de extrema importância para a sua sobrevivência. Considere as afirmações abaixo, referentes ao comportamento osmótico desses peixes. I. Os peixes teleósteos marinhos são menos concentrados que o ambiente. II. Os peixes teleósteos de água doce fazem a captação de sias pelas brânquias. III. Os peixes teleósteos marinhos perdem água para o ambiente por osmose. IV. Os peixes teleósteos de água doce bebem água 
para realizar a regulação osmótica. Quais estão corretas? a) Apenas I e II. b) Apenas I e III. c) Apenas III e IV. d) Apenas I, II e III. E) I, II, III, e IV” (p. 99).

A categoria "Saiba Mais" busca facilitar o aprendizado dos alunos, por meio de elementos diferenciados, que estimulam a criatividade e o senso crítico dos alunos (TEMP, 2011). Nos livros analisados, essa PP teve pouco destaque ou até mesmo nenhuma prática encontrada, como é o caso em B1, B2, B5 e B6. Nos outros livros, essa PP foi encontrada, mas em número reduzido, como em B3, no qual foram encontradas apenas 2. Nos livros de Ciências, essa PP teve um maior destaque, sendo em $\mathrm{C} 7$ encontradas dezoito práticas. Nesta categoria e na categoria "Leitura Complementar" foi encontrada uma diferença bastante significativa entre o número de práticas. A coleção de Gowdak e Martins (2015) foi a que mais apresentou e a de Amabis e Martho (2016) a que menos apresentou essa categoria.

Na categoria "Leitura Complementar" foram encontradas 317 práticas, sendo 192 nos livros de Ciências, em maior número em $\mathrm{C}$, como por exemplo: "O que significam os itens da tabela de informação nutricional nos rótulos" (p. 57). Já C4 foi o livro que menos apresentou essa categoria.

Nos livros de Biologia foram localizadas 125 práticas, sendo 48 em B3: "Pode-se dizer que vivemos de luz? É verdade! Vivemos de luz. Não é à toa que muitas civilizações antigas viram o Sol como um deus. Os assírios personificavam o nosso conhecimento astro-rei como o deus Shamash e os egípcios o chamavam de Rá. Na visão mítica egípcia, [...]. Vivemos de luz, sim, mas indiretamente. Não acredite se alguém disser que parrou de se alimentar e passou a viver diretamente de luz solar; a ciência contesta essa ideia. É melhor deixar isso com os especialistas: os seres fotossintetizantes" (p. 192). Este trecho foi encontrado no capítulo denominado de fluxo de energia e ciclo da matéria na natureza.

B5 apresentou quatorze práticas nesta categoria: "As pérolas. Em certas espécies de ostras ocorre a formação de pérolas. Se um parasita ou um pequeno grão de areia penetra entre o manto e a concha, inicia-se uma reação e defesa do organismo e o manto passa a secretar uma camada de madrepérola (camada nacarada), que envolve esse corpo estranho formando uma pequena esfera. Essa cresce envolta em uma bolsa do próprio manto, que também produz a concha. Os cultivadores de pérola induzem pequenas esferas feitas das próprias conchas entre o manto e a concha das ostras, provocando no animal a reação da proteção, que após alguns anos leva à produção de pérola. Estas não devem ser confundidas com as pérolas sintéticas, produzidas industrialmente com diferentes materiais" (p. 69).

Estas "Leituras Complementares" abordam assuntos que, por vezes, no decorrer do capítulo não foram muito debatidos, fato, também, percebido nos estudos de Kupske et al. (2012).

Para facilitar a contextualização dos conteúdos, a leitura complementar e as curiosidades buscam aproximar o texto da realidade do aluno, visando atrair sua curiosidade e atenção
(BATISTA et al., 2010). Boa parte dos livros apresenta leituras complementares, mas somente em certos capítulos. As obras de Amabis e Martho (2016) e de Gowdak e Martins (2015) foram as que mais e menos apresentaram leituras complementares, respectivamente. No entanto, quase todos os livros apresentaram curiosidades, com destaque para os livros do autor Gewandsznajder (2015).

$\mathrm{Na}$ categoria "Curiosidade" foram identificadas 63 práticas, sendo todas encontradas nos livros de Ciências. Nesta categoria, C4 predominou com 15 PP e C5 foi o livro que apresentou o menor número deste tipo de prática, sendo três no total. Como exemplo, em C1 (p.159): “A altitude é a distância vertical entre um ponto e o nível do mar".

De acordo com Vasconcelos e Souto (2003, p. 101), livros "[...] didáticos precisam, sem dúvida, conter ferramentas que incitem a discussão sobre o conteúdo teórico a fim de permitir sua conversão em conhecimento. Estamos falando em produção de conhecimento útil, aplicável e presente no cotidiano do aluno". Com isso, PP envolvendo atividades de texto e temas para discussão são de extrema importância para a contextualização e a problematização de conhecimentos. A coleção de Júnior, Sasson e Júnior (2016) apresentou uma maior quantidade de PP envolvendo essa categoria, enquanto a coleção de Gowdak e Martins (2015) apresentou menor número.

$\mathrm{Na}$ categoria "Atividade de Texto" foram encontradas 369 PP. Na coleção de Biologia, os livros B1, B2 e B3 apresentaram apenas nove práticas no total nesta categoria, sendo que B6 foi o livro que apresentou o maior número: "Aploliploidia: a possibilidade de especiação rápida. Os híbridos interespecíficos, como a mula, são estéreis. Isso ocorre em função do fato de os cromossomos do gameta paterno não serem homólogos[...]. 1- O texto menciona que, um caso de alopoliploidia, ocorre uma mitose anômala em uma célula inicial de um híbrido interespecífico. Em que momento da divisão celular acontece essa anomalia? 2- Por que a existência de pares de cromossomos homólogos é considerada um requisito fundamental para a fertilidade de uma planta ou de um animal diploide?" (p. 197).

Nos livros de Ciências foram encontradas 144 práticas, sendo 28 em C6, o LD com maior número de práticas nessa categoria, e C3 o que apresentou o menor número de práticas: "Leia o texto a seguir e responda às questões propostas. Aplicações comerciais das enzimas. Um estudante misturou pedaços de abacaxi maduro e fresco com gelatina recém-preparada. Quando retirou a gelatina da geladeira, observou que essa apresentava várias partes moles, em vez da consistência normal. A explicação é que o abacaxi possui enzimas que digerem proteínas [...]. 1- A digestão do amido começa na boca, pela ação da amilase salivar. Imagine que o professor ponha saliva em um recipiente, ferva por alguns minutos e a despeje em um pouco de farinha de trigo. Você acha que essa saliva vai começar a digerir o amido. Justifique. 2- Que enzima pode ser adicionada ao sabão em pó para 
ajudar a remover manchas de gordura?” (p. 59). A partir dos exemplos, pode-se perceber uma evolução na forma de escrita da atividade encontrada nos livros do Ensino Fundamental para as encontradas nos livros de Ensino Médio.

Dos quatorze livros analisados, apenas sete destes apresentaram a categoria "Tema para Discussão", sendo encontradas 178 práticas, todas presentes nos Livros de Ensino Fundamental, com uma exceção para $\mathrm{C} 1$ que não apresentou nenhuma PP nesta categoria, além disso cabe ressaltar que no Ensino Médio não foi encontrada nenhuma prática. Este tipo de prática é importante, pois possibilita o debate sobre determinado assunto, de modo que todos possam expor suas opiniões. Além disso, esse tipo de prática faz os alunos se tornarem mais críticos e reflexivos. Um exemplo dessa PP se encontra em C4: "Por que as pessoas que estão em outras partes da Terra não caem? Por que um navio flutua na água?" (p. 144).

A categoria "Sugestão de aula Práticas" é importante no aprendizado do aluno, pois, segundo Fagundes (2007, p. 333):

[...] em aulas práticas, o aluno deixa de ser ouvinte e repetidor de informações fornecidas pelo professor ou pelo livro para se tornar sujeito de sua aprendizagem, refletindo conscientemente sobre os temas estudados, pois, num experimento, o aluno pode prever o que pode acontecer e depois relacionar os resultados com a teoria previstas.

Porém, percebe-se que as práticas se apresentam imperativas, o que, segundo Santos et al. (2015) limita a discussão sobre a execução e as possíveis adaptações dessas práticas à realidade escolar. Além disso, as práticas imperativas estimulam a mera reprodução das informações transmitidas (RAMOS; ANTUNES; SILVA, 2010).

Nesta categoria foram classificadas 139 práticas, sendo 103 nos livros de Ciências, tendo como destaque C8 com 21 práticas: "Densidade de Líquidos e de Sólidos. Objetivos: Compare a densidade de dois líquidos. Determinar, experimentalmente, a densidade de líquidos e de um corpo sólido. Material: Duas provetas graduadas, idênticas e com capacidade de $50 \mathrm{~mL} ; 600 \mathrm{~mL}$ de água; $500 \mathrm{~mL}$ de óleo; uma balança; uma pedra que caiba na proveta. Parte 1Procedimento A. Meça separadamente as massas das duas provetas vazias, utilizando a balança, e anote esses valores em seus cadernos. B. Coloque $300 \mathrm{~mL}$ de água em uma das provetas e $300 \mathrm{~mL}$ de óleo na outra. C. Utilizando a balança, meça as massas das duas provetas que contêm água e óleo. Anote esses dois valores de massa em seu caderno. D. Do valor obtido, de cada massa, subtraia o valor da massa da proveta e, também, anote no caderno esses novos valores. Questões e Conclusões. 1. Por que é preciso medir a massa das duas provetas vazias? 2. Em sua opinião, qual desses líquidos é o mais denso, a água ou óleo? 3- Calcule as densidades da água e do óleo, em $\mathrm{g} / \mathrm{cm}^{3}$. Lembre-se de que $1 \mathrm{~mL}=1 \mathrm{~cm}^{3}$. 4. A sua precisão estava correta a respeito das densidades dos líquidos? Parte 2 Procedimento A. Coloque $250 \mathrm{~mL}$ de água na proveta. B. Mergulhar a pedra na proveta e anote a nova graduação correspondente ao nível da água. C. Meça a massa da pedra na balança e anote. Questões e Conclusões 1. O que é preciso conhecer de um corpo sólido para calcular a sua densidade? 2. A que corresponde o volume de água deslocado na proveta depois de mergulhada a pedra? 3. Quais são as informações necessárias para determinar a densidade da pedra? 4. Determine a densidade da pedra, em g/ $\mathrm{cm}^{3 "}$ (p. 23).

Nos livros de Ciências, os que menos apresentaram esta forma de prática foram C3 e C7. Nos livros de Biologia foram encontradas 36 práticas, estando em maior número em B1 (12), já os livros B3, B4 e B5 foram os que apresentaram menos PP, como, por exemplo, em B5: "Fungos do apodrecimento. Problematização: alimentos emboloram em qualquer condição ou há condições que favorecem o surgimento de fungos? Material: 3 pires (ou 3 pratos de plástico); 2 sacos de plástico transparente: 3 laranjas bem maduras, meio amassadas. Procedimentos: molhe bem as três laranjas e faça a montagem: Pires A- laranja exposta ao ar. Pires B- laranja exposta ao ar por 3 dias e, depois, colocadas dentro de um saco plástico mantido na geladeira. Pires C- laranja coberta com um saco plástico desde o início do experimento. Mantenha os pires $\mathrm{A}$ e $\mathrm{C}$ expostos à luz difusa. Após 7 a 10 dias, observe e compare o aspecto das laranjas. Anote os resultados em seu caderno. Análise de informações: descreva, em seu caderno, as diferenças entre as laranjas. 1- Quais foram as cores dos fungos que cresceram nas cascas? 2- Em qual dessas os fungos (bolores) se desenvolveram mais? 3- Elabore uma justificativa, utilizando as variáveis de cada montagem, para tentar explicar as diferenças observadas". (p. 37).

Segundo Fernandes, Güllich e Kierepka (2012, p.116), estas atividades

[...] são apresentadas com comandos que ditam exatamente o que o aluno deve fazer e em qual momento, Pegue,... coloque,... faça... Estes comandos sugerem que a ciência seja pensada como cópia de modelos já existentes e não como criadora e investigativa que é.

Quanto à análise da categoria "Questionário" foram classificadas 326 práticas e os livros de Biologia foram os que menos as apresentaram (31), das quais $17 \mathrm{em} \mathrm{B1}$ como: "Na sua opinião, a célula foi "descoberta" em 1665, quando Hooke visualizou pela primeira vez as cavidades da cortiça, ou quando Scheiden e Schwann propuseram a teoria celular, em 1838-1839? Pense nisso quando estudar o capítulo" (p. 66).

Nos livros de Ciências foram encontradas 295 práticas, sendo 51 em C5 e 25 em C4, que apresentaram o maior e o menor número de práticas, respectivamente. Como exemplo: "Costuma-se dizer que os insetos estão muito bem equipados para a vida terrestre. Você sabe por quê?" (C2, p. 145).

Esta categoria envolve atividades reflexivas, que levam o aluno ao aprofundamento do conteúdo por meio de questões práticas, que o instigam à pesquisa (KUSPE et al., 2012). Essas práticas foram encontradas em muitos livros, refletindo a importância pedagógica desse recurso no ensino. O livro do 
autor Gowdak e Martins (2015) foi o que mais apresentou essa prática, enquanto o livro de Amabis e Martho (2016) e Júnior, Sasson e Júnior (2016) foram os que menos apresentaram essa prática.

As "Atividades em Grupo" visam construção coletiva de conhecimentos, possibilitando a troca de experiências e de percepções acerca de um determinado assunto (SBDG, 2006). Nos livros avaliados, essa PP não teve muito destaque, sendo encontradas 78 práticas, principalmente, em Gowdak e Martins (2015) e, em menor número, em Júnior, Sasson e Júnior (2016).

Das 78 práticas encontradas, 13 foram nos LD de Biologia, como em B5: "Em grupo, estabeleça uma relação entre alguma atividade cotidiana dos integrantes do grupo, o tipo de degradação ou impacto ambiental causado e a ameaça à permanência de espécies no planeta que habitamos" (p. 84).

Nos livros de Ciências foram encontradas 65 práticas, sendo que C7 apresentou o maior número (13), enquanto C8 apresentou apenas duas práticas classificadas nesta categoria. Por exemplo, em C7 (p. 78): "Em grupos, pesquisem a respeito dos seguintes problemas relacionados ao sistema digestório: azia, úlceras e desidratação. Em seguida, discuta-os com os outros grupos da sala e, se possível, com outras turmas da escola.". A maioria das atividades em grupo encontradas nos livros de Ciências traziam pesquisas como atividade a ser realizada em grupo.

A PP envolvendo Tabela/Gráfico busca tornar a interação entre livro, professores e alunos mais fácil e objetiva, pois oferecem recursos para exercitar o conhecimento e melhorar a compreensão do conteúdo (VASCONCELOS; SOUTO, 2003). No presente trabalho, essas PP não foram muito exploradas, sendo que os livros de Gewandsznajder (2015) e de Júnior, Sasson e Júnior (2016) apresentaram essa PP em maior e menor número, respectivamente.

Nesta categoria foram encontradas 78 práticas, sendo 53 gráficos e 25 tabelas. Dos livros de Ciências analisados, o que menos se destacou foi o C6, no qual foi encontrada apenas 1 PP. Já C4 foi o que apresentou mais práticas (18): “Observe o gráfico a seguir e faça o que se pede:

Figura 3 - Interpretação de Gráficos

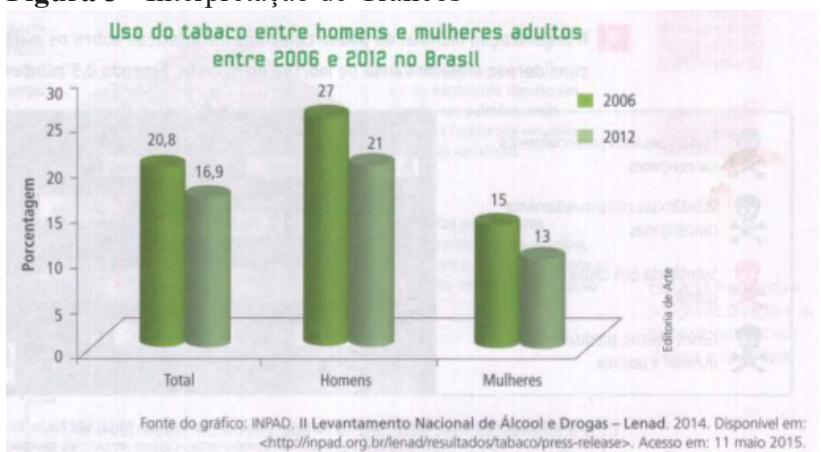

Fonte: C4.

a) O que ocorreu com o número de homens e de mulheres fumantes entre 2006 e 2012 no Brasil? b) Elabore hipótese que expliquem o fato mencionado no item anterior" (p. 89).

Nos livros de Biologia foram encontradas dezoito práticas, sendo que B6 não apresentou prática nestas categorias, já B4 apresentou cinco práticas: “O gráfico A representa a quantidade de água existente em tecidos dos dentes, dos ossos, dos rins e dos músculos de um animal. O gráfico B mostra o consumo de oxigênio desses tecidos, sem, no entanto, identificá-los. Com base no que você aprendeu neste capítulo sobre os fatores que influem na quantidade de água em um tecido, identifique os tecidos 1, 2, 3 e 4 do gráfico B e justifique a sua opinião.” (B4, p.34). A Figura 4 apresenta os gráficos que acompanham o exemplo.

As ilustrações em LD subsidiam a compreensão dos assuntos estudados, tornando as informações do texto mais claras aos leitores (VASCONCELOS; SOUTO, 2003). Assim, os esquemas de representação, bem como tirinhas e palavras cruzadas são importantes recursos da aprendizagem. De acordo com Choppin (2004, p. 553), o LD:

[...] põe em prática métodos de aprendizagem, propõe exercícios ou atividades que, segundo o contexto, visam a facilitar a memorização dos conhecimentos, favorecer a aquisição de competências disciplinares ou transversais, a apropriação de habilidades, de métodos de análise ou de resolução de problemas, etc.

Figura 4 - Exemplos de Gráficos.

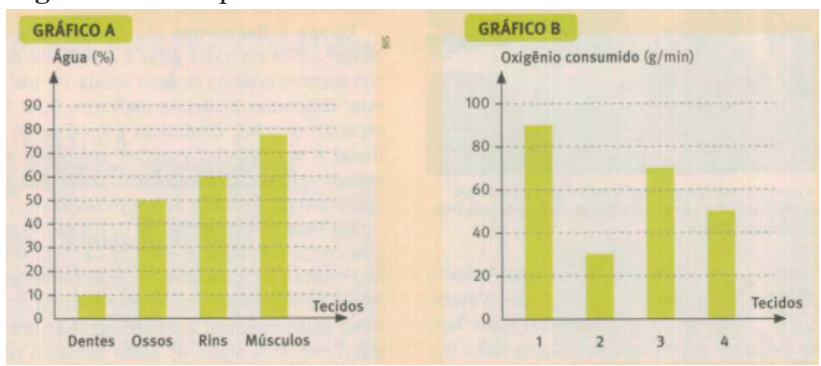

Fonte: B4.

Os livros estudados apresentaram poucas práticas relacionadas a esses temas, sendo que esses recursos poderiam ter sido mais explorados nos livros analisados.

A categoria "Tirinhas" foi encontrada em 70 práticas. Além disso, esta prática foi encontrada apenas nos livros de Ciências, exceto $\mathrm{C} 3$, que não apresentou nenhuma prática nessas categorias. Dentre estes, C7 apresentou 17 práticas nessa categoria (Figura. 5).

Figura 5 - Exemplo de tirinha

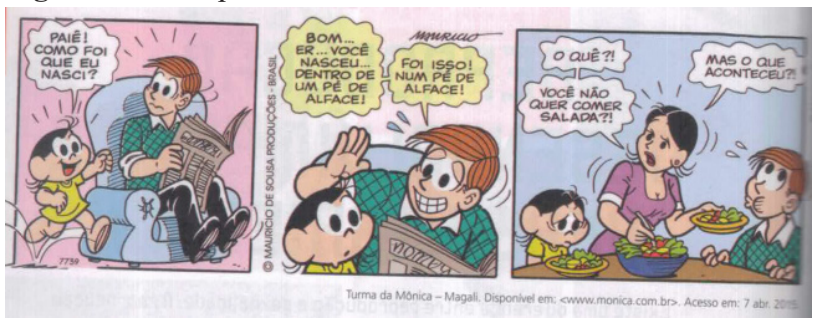

Fonte: C7.

Os esquemas são considerados ilustrações que possibilitam uma analogia com os conceitos abstratos estudados 
(RICHTER; HERMEL, 2016). Na categoria "Esquema de Representação" foram encontradas 66 práticas, sendo 8 nos livros de Biologia e 58 nos livros de Ciências. O livro que mais apresentou este tipo de prática foi C8: "Observe o esquema. Sabe-se que explosões nucleares liberam diversos tipos de partículas, [...]" (p. 148). A Figura 6 apresenta o esquema que acompanha o exemplo.

Figura 6 - Esquema de Representação

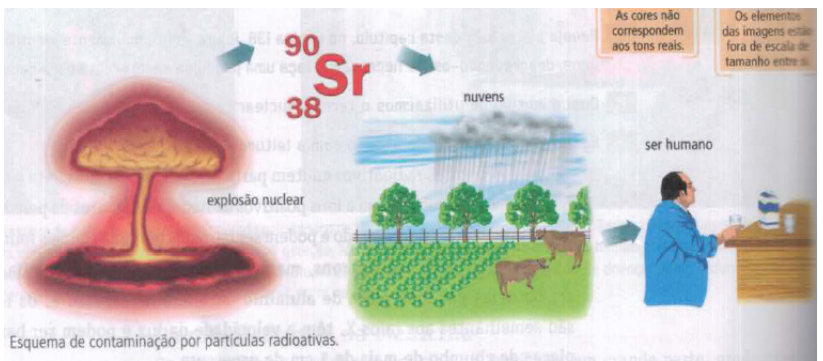

Fonte: C8.

Dos livros de Biologia, B4 foi o que mais apresentou práticas (Figura. 7). Nesses esquemas foram abordados fenômenos rápidos, nos quais vários fenômenos puderam ser avaliados ao mesmo tempo.

Figura 7 - Esquema de representação

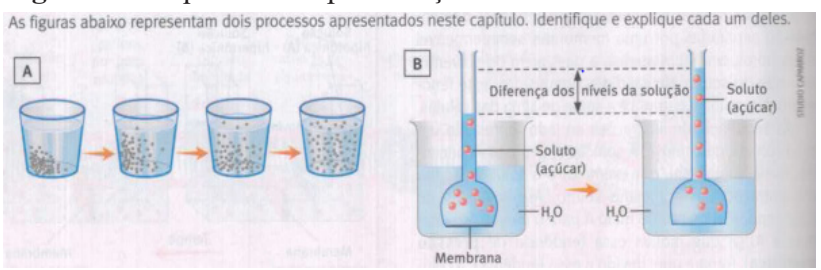

Fonte: B4.

Nos livros de Biologia B4, B5 e B6 foram encontradas "Sugestões de Projetos Interdisciplinares", sendo que cada um destes livros apresentou 4 práticas nesta categoria, como em $\mathrm{C} 4$, que sugeriu aos alunos pesquisar interdisciplinarmente sobre "Os Limites da Vida" (p. 47) e B6 (p. 57), que traz como sugestão trabalhar de maneira interdisciplinar os "Diferentes olhares sobre a saúde humana".

As sugestões de Projetos Interdisciplinares são importantes, pois trazem consigo uma introdução sobre os assuntos, o modo de ação, sendo que a maioria das vezes era proposto que estas atividades fossem realizadas em grupos, e um tópico de fechamento que traz atividades e ideias de como discutir os assuntos trabalhados.

A interdisciplinaridade tem o papel de interagir com outras áreas do conhecimento, promovendo uma maior interação entre aluno, professor e seus cotidianos (BONATTO, 2012). Esa surge da necessidade de haver respostas para uma provável fragmentação do conteúdo abordado nas diferentes disciplinas, esta é uma ferramenta muito importante que promove diálogos entre estas diferentes áreas do conhecimento (UMBELINO; ZABINI, 2014).

\section{Conclusão}

A partir desta pesquisa se pode perceber que os LD apresentam muitas PP, porém, em muitos desses se sobressaem apenas algumas práticas como "Atividades Reproducionistas" e "Pense e Responda", sendo outras deixadas de lado, como "Sugestões de Projetos Interdisciplinares" e "Exercícios Comentados". Além disso, cabe ressaltar que nem todas as PP analisadas foram encontradas nos LD, significando, assim, que ainda é necessário um avanço na diversidade das PP propostas nos LD.

Estudos como esse são importantes, pois podem auxiliar os professores na escolha dos seus livros, já que o LD, muitas vezes, acaba por ser o único meio de estudo e de pesquisa para o aluno. Assim, é necessário um aumento nas articulações entre as pesquisas produzidas por acadêmicos e os trabalhos docentes.

A partir deste trabalho se percebeu a necessidade e a importância de $\mathrm{PP}$ envolvendo atividades que levem o aluno à reflexão e ao pensamento crítico sobre a realidade que o cerca, e não apenas a reproduzir aquilo que foi estudado em cada capítulo.

Além disso, para a eficiência das PP, é necessário que os professores utilizem as metodologias que os LD oferecem, como por exemplo os links e as demais sugestões, não os negligenciando, pois estes são métodos de ensino e de aprendizagem que podem agregar muito na consolidação do conhecimento.

\section{Referências}

APPLE, M. Educação e poder. Porto Alegre: Artes Médicas, 1989.

BATISTA, A.A.G. Recomendações para uma política pública de livros didáticos. Brasília: MEC, 2001.

BATISTA, V.A.; CUNHA, M.M.S.; CÂNDIDO, A.L. Análise do tema virologia em livros didáticos de biologia do ensino médio. Rev. Ensaio, v.12, n.1, p.145-158, 2010. doi: https://doi. org/10.1590/1983-21172010120109.

BONATTO, A. et al. Interdisciplinaridade no ambiente escolar. In: SEMINÁRIO DE PESQUISA EM EDUCAÇÃO DA REGIÃO SUL, 9., 2012, Caxias do Sul. Anais... Caxias do Sul, RS: Universidade da Caxias do Sul, 2012.

BRASIL. Decreto-lei n 1006, de 30 de dezembro de 1938. Estabelece as condições de produção, importação e utilização do livro didático. Lex: Coleção de Leis do Brasil, v. 4, p. 350, 1938.

BRASIL. Decreto ${ }^{\circ}$ 91.542, de 19 de agosto de 1985. Institui o Programa Nacional do Livro Didático, dispõe sobre sua execução e dá outras providências. Lex: Coleção de Leis do Brasil, 1985.

BRASIL. Ministério da Educação e Cultura. Lei de Diretrizes e base da Educação Nacional - LDB. Centro de documentação do Congresso Nacional. Brasília: MEC, 1996.

BRASIL. Ministério da Educação e Cultura. Secretaria de educação fundamental. Parâmetros curriculares nacionais: Parâmetro nacional de língua portuguesa. Brasília: MEC/SEF, 1997.

BRASIL. Ministério da Educação. Fundo Nacional de Desenvolvimento da Educação. PNLD: Dados estatísticos. 
Brasília: MEC, 2015.

BRASIL. Ministério da Educação. Programa Nacional do Livro Didático para o Ensino Médio-PNLEM. Brasília: MEC, 2019.

CHOPPIN, A. História dos livros e das edições didáticas: sobre o estado da arte. Educ. Pesq., v.30, n.3, p.549-566, 2004. doi: 10.1590/S1517-97022004000300012.

DELIZOICOV, N.C. O professor de ciências naturais e o livro didático (no Ensino de Programas de Saúde). Florianópolis: Universidade Federal de Santa Catarina, 1995.

FAGUNDES, S.M.K. Experimentação nas Aulas de Ciências: um meio para a formação da autonomia? In: GALIAZZI, M.C. et al. Construtivismo curricular em rede na educação em ciências: uma porta de pesquisa na sala de aula. Ijuí: Ed. Unijuí, 2007. p.317-336.

FERNANDES, A.C.L.; GÜLLICH, R.I.C.; KIEREPKA, J.S.N. Práticas pedagógicas no livro didático de ciências no Ensino Fundamental. Rev. Ciênc. Hum., v.13, n.20, p.111-122, 2012.

GALUCH, M.T.B.; CROCHÍK, J.L. Propostas Pedagógicas em Livros Didáticos: Reflexão sobre a pseudoformação. Cad. Pesq., v.46, n.159, p.234-258, 2016. doi: https://doi. org/10.1590/198053143218.

KRASILCHIK, M. O professor e o currículo das ciências. São Paulo: EPU, 1987.

KUPSKE, C. et al. As atividades pedagógicas de biologia celular e histologia no contexto do livro didático de Ciências. In: ANPED SUL, 9., Caxias do Sul, 2012. Anais ... Caxias do Sul, 2012.

LÜDKE, M.; ANDRÉ, M.E.D.A. Pesquisa em educação: abordagens qualitativas. São Paulo: EPU, 2001.

MEGID NETO, J.; FRACALANZA, H. O livro didático de ciências: problemas e soluções. Ciênc. Educ., v.9, n.2, p.147-157, 2003. doi: https://doi.org/10.1590/S1516-73132003000200001.

PECHULA, M.R.; DEL POZZO, L.; BOCANEGRA, C.H. Considerações sobre o ensino de ciências e o uso de materiais didáticos midiáticos: possibilidades e limites. Contrapontos, v.12, p.145-153, 2012

RAMOS, L.S.; ANTUNES, F.; SILVA, L.H.A. Concepções de professores de Ciências sobre o ensino de Ciências. Rev. SBEnbio, v.3, p.1666-1674, 2010.

RIBEIRO, W.A.; GULLICH, R.I. Ensino de botânica na perspectiva do livro didático de biologia do ensino de médio. In: CONGRESSO INTERNACIONAL DE EDUCAÇÃO CIENTÍFICA E TECNOLÓGICA, 4., 2017, Santo Ângelo.
Anais... Santo Ângelo, RS: Universidade Regional Integrada do Alto Uruguai e das Missões, 2017.

RICHTER, E.; HERMEL, E.E.S. A biologia celular nos livros didáticos de biologia: uma análise histórica de conteúdo (19232004). Rev. SBEnBIO, v.9, p.3191-3202, 2016.

SANTOS, S.A. et al. Investigando atividades práticas nos livros didáticos de biologia. Rev. Destaques Acadêm., v.7, n.3, 2015.

SIEMSEN, G.H.; OLIVEIRA, S.; LORENZETTI, L. Parâmetros de alfabetização científica e alfabetização tecnológica na Educação em Química: analisando a temática ácidos e bases. In: ENCONTRO NACIONAL DE ENSINO DE QUÍMICA, 18., Florianópolis, 2016. Anais... Florianópolis, 2016

SILVA, M.A.A fetichização do livro didático no Brasil. Educ. Realidade, v.97, n.3, p.803-821, 2012. doi: https://doi. org/10.1590/S2175-62362012000300006.

SORGE, C.J, et al. Atividades pedagógicas no contexto do livro didático de ciências. Ensino Ciênc. Tecnol., v.3, p.21-29, 2013. doi: https://doi.org/10.1590/S2175-62362012000300006.

SOUZA, A.H.S.; VIERA, R.D.; MELO, V. F. Atividades argumentativas em livros didáticos de Física do PNLD 2015: o incentivo ainda é escasso. Amazônia Rev. Educ. Ciênc. Matem., v.13, p.100-115, 2016. doi :http://dx.doi.org/10.18542/amazrecm. v13i25.3751.

TEMP, D.S. Facilitando a aprendizagem em genética: uso de um modelo didático e análise dos recursos presentes em livros de biologia. Santa Maria: Universidade Federal de Santa Maria, 2011 .

UMBELINO, M.; ZABINI, F. O. A importância da interdisciplinaridade na formação do docente. In: SEMINÁRIO INTERNACIONAL DE EDUCAÇÃO SUPERIOR, 1., 2014, Sorocaba. Anais... Sorocaba, SP: Universidade de Sorocaba, 2014

VASCONCELOS, S.D.; SOUTO, E. O livro didático no ensino fundamental - proposta de critérios para análise de conteúdo. Ciênc. Educ., v.9, n.1, p.93-104, 2003. doi: https://doi. org/10.1590/S1516-73132003000100008.

XAVIER, M.C.F.; FREIRE, A.S.; MORAES, M. O. A nova (moderna) biologia e a genética nos livros didáticos de biologia no ensino médio. Ciênc. Educ., v.12, n.3, p.275-289, 2006. doi: https://doi.org/10.1590/S1516-73132006000300003.

ZACHEU, A.A.P.; CASTRO, L.L.O. Dos tempos imperiais do PNLD: a problemática do livro didático no Brasil. In: JORNADA DO NÚCLEO DE ENSINO DE MARÍLIA, 14., Marília. Anais... Marília: Unesp, 2015. 